\title{
Variation between Geographical Populations of Lutzomyia (Nyssomyia) whitmani (Antunes \& Coutinho, 1939) sensu lato (Diptera:Psychodidae:Phlebotominae) in Brazil
}

\author{
Elizabeth F Rangel, Ralph Lainson*, Adelson A Souza*, Paul Ready**, Alfredo \\ CR Azevedo
}

\begin{abstract}
Departamento de Entomologia, Instituto Oswaldo Cruz, Av. Brasil 4365, 21045-900 Rio de Janeiro, RJ, Brasil *Instituto Evandro Chagas, Belém, PA, Brasil **The Natural History Museum, London, UK
\end{abstract}

Phylogenetic analysis of morphometric and biological characters indicated that there are two distinct forms of Lutzomyia whitmani in Brazil: one is present both north and south of the River Amazonas in the State of Pará while the other occurs in northeast Brazil, in the State of Ceará, and further south, including the type locality in State of Bahia. The Amazonian form is reportedly neither strongly anthropophilic nor synanthropic, and it is the vector of Leishmania shawi; whereas the southern form is often collected peridomestically, while biting man, and has been found infected with Le.(V.) braziliensis. The ratio of the length of the genital filaments to that the genital pump was found to be consistently smaller in males of the Amazonian populations. A middle repetitive DNA element was isolated by differentially screening a genomic library made using Amazonian material, and the sequence was diagnostic for this form of Lu. whitmani (being absent or occurring in low copy number in the southern form). The total evidence suggests there are at least two, geographically-isolated forms of $\mathrm{Lu}$. whitmani, which may represent different cryptic species.

Key words: Lutzomyia whitmani - cryptic species - cutaneous leishmaniasis

Lutzomyia (Nyssomyia) whitmani Antunes \& Coutinho, 1939 was first described from Ilhéus, State of Bahia, Brazil, and has since been recorded (sensu lato) in various other parts of Brazil, Argentina, French Guiana, Paraguay and Peru (Young \& Duncan 1994). In Brazil, Lu. whitmani s.l. is found in habitats ranging from dense primary rain-forest of the Amazon Region to the northeastern and southeastern parts of the country where little forest now remains, and where this sandfly has adapted to human dwelling places and peridomestic animal sheds.

With regards the importance of $L u$. whitmani s.l. as a vector of Leishmania, the most concrete evidence comes from States of Bahia and Ceará, where it has been found infected with Le.(V.) braziliensis (Hock et al. 1986, Ryan et al. 1990, Azevedo et al. 1990, Queiroz et al. 1991). In northern Paraná it was found to be the predominant sand fly species in endemic areas of cutaneous leishmaniasis, although its role as a vector there has still to be established (Teodoro et al. 1991). In the States of São Paulo and Minas Gerais it is similarly suspected as an important vector of $L e$.

Work supported by CNPq, Wellcome Trust and British Council, and forming part of the PhD Thesis of the first author.

Received 15 May 1995

Accepted 18 October 1995
(V.) braziliensis, by virtue of its highly anthropophilic feeding habits, high density in the endemic areas and very common presence in and around human dwelling places or animal sheds (Barretto 1943, Forattini 1960, Mayrink et al. 1979, Taniguchi et al. 1991, Tolezano et al. 1992).

In Amazônia, workers on the eco-epidemiology of cutaneous leishmaniasis have long been puzzled by the very different habits of $L u$. whitmani s.l., compared with its behaviour in other parts of Brazil. Thus, it is essentially silvatic, being found in modest numbers on the trunks of the larger trees. It is of low anthropophily, and has yet to be found invading houses or the peridomestic habitat (Lainson et al. 1979, Ready et al. 1986). It has been found infected with Leishmania on a number of occasions, however, with a parasite identified as Le. (V.) guyanensis (Lainson et al. 1979), but which might, in fact, have been Le. (V.) shawi and, more frequently, with this latter species - a recently described parasite of monkeys, sloths, procyonids and man (Lainson et al. 1989, Shaw et al. 1991).

These contrasting characteristics of the silvatic population of a sand fly which is seemingly indistinguishable from the type species of $\mathrm{Lu}$. whitmani raised strong doubts as to its real identity (Lainson 1988). How was it that this sand fly could occupy such different habitats and have such different feeding habits? Is $L u$. whitmani simply a sand fly with 
an extraordinary capacity for adaptation to new, man-made environments, or is it a complex of cryptic species?

It was with these questions in mind that the following biological, morphological and biochemical comparison was made of populations of $L u$. whitmani s.l. from different parts of Brazil.

\section{MATERIALS AND METHODS}

Lu. whitmani from northeast Brazil - Material from Ilhéus, Bahia, the type-locality, was clearly indispensible for our comparative study and, in addition, we also obtained flies from Baturité, Ceará. In both areas (Fig. 1) the collections, by different methods, were made simultaneously in and around human dwelling-places and animalsheds, between 6:00 and 9:00 hr. In the houses, sand flies were aspirated from walls or human bait: in the peri-domestic habitat they were obtained in man-baited Shannon-traps (Sherlock \& Pessoa, 1964), aspirated from dogs or equines, or caught in miniature CDC light-traps (Sudia \& Chamberlain 1962, Gomes et al. 1985) placed in animal shelters.

Lu. whitmani s.l. from north Brazil - We chose three widely separated areas of high, primary rainforest. The first at an altitude of about $700 \mathrm{~m}$ in the range of hills known as the Serra dos Carajás (Ward et al. 1973) in south Pará; the second in lowland forest at Dom Elizeu, southern Pará; and the third in a hilly region near Monte Dourado, northern Pará (Fig. 1). In these areas the collections were made between 17:30-20:30 hr, in the forest, using human bait; in CDC light-traps set at both $1.0 \mathrm{~m}$ from the ground and in the canopy, from 17:00-07:00 hr; or by aspirating the flies from the trunks of large trees in the early morning.

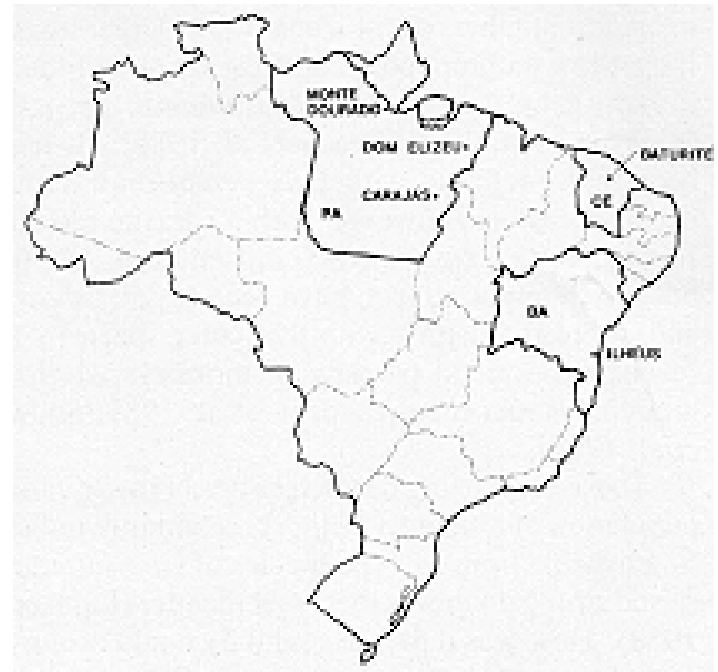

Fig. 1: Lutzomyia whitmani s.l. Studied populations from Brazil, in the States of Pará, Ceará and Bahia (PA, CE, BA).
Morphology - We examined 20 specimens (10 males and 10 females) and we used morphological features routinely utilized in the identification of sand fly species (Young \& Duncan 1994), together with others, less commonly used, recommended by the CIPA Group (Bermudes et al. 1991), as follows:

The head: palpal formula of the female and the male, number of hind teeth of the cibarium, spines and striae of pharynx, proximal and distal prolongation of the ascoids, teeth of the maxilla.

The thorax: location and intensity of pigmentation of the mesonotum, scutellum, pleura and "hipsi" (CIPA terminology: = coxa).

The abdomen: dermal papillae of tergites, shape of the terminal portion of the genital filaments, relation of the lateral lobe/paramere, shape of aedeagus, number and distribution of style spines and localization of the internal spine, shape and size of the coxite setae, shape of paramere, shape of spermathecal body, number and appearance of the annulations of the spermathecal body, axis of the spermathecal head, organization of the spermathecal body and the individual duct, appearance and length of the individual duct, appearance and length of the common duct.

Morphometry - The length and/or width of the following structures were measured in 10 males and 10 females.

The head: length of cibarium of female, length of 2nd, 3rd and 5th palpal segments of male and female.

The thorax: maximum width of the wings, length of 5 th radial vein and $\alpha, \beta, \gamma$ and $\delta$ of both sexes, length of tibia and femur in both sexes.

The abdomen: length of coxite, style, lateral lobe, genital pump and genital filaments, size of the style compared with that of the coxite, genital filaments/genital pump ratio.

Statistical analysis - Means and standard deviations were calculated by accepted methods (see Acknowledgements). The T Parametric test was used for difference between means. When the No Parametric test was used, the contrast Scheffe was applyied (Armitage 1971).

Biochemical studies - DNA probe - Sand flies from Ilhéus and Dom Elizeu were bred in the insectary at the Instituto Evandro Chagas and males and females of the first generation were snap-frozen in liquid nitrogen. Those from Monte Dourado and Baturité were identified after collection, using a binocular microscope with cold-light illumination, and at once stored in liquid nitrogen. Sand flies of two other species used as controls, were from laboratory colonies of $L u$. intermedia and Lu. flaviscutellata from the Instituto Oswaldo Cruz and the Instituto Evandro 
Chagas, respectively. These, too, were stored in liquid nitrogen.

All specimens for DNA studies were taken to London on solid carbon dioxide and then stored at $-80^{\circ} \mathrm{C}$. DNA extraction for library construction was from the Dom Elizeu, Pará flies, by the method of Ish-Horowicz (1982) following the procedure of Ready et al. (1991), and the resulting material was stored at $4^{\circ} \mathrm{C}$.

The disposable plastic tip of a Gilson pipette was used to grind the sand fly remains in $15 \mu \mathrm{l}$ Tris Buffer $[10 \mathrm{mM}$ Tris, $\mathrm{HCl} \mathrm{pH} 7.5,60 \mathrm{mM}$ $\mathrm{NaCl}, 10 \mathrm{mM}$ EDTA, $0.15 \mathrm{mM}$ spermine, 0.15 $\mathrm{mM}$ spermidine, $5 \%(\mathrm{w} / \mathrm{v})$ sucrose] and the homogenate then mixed with a further $85 \mu \mathrm{l}$ of this grinding buffer together with $10 \mu \mathrm{l}$ of a sodium dodecyl-sulphate (SDS) buffer [1.25\% (w/ v) SDS, 0.3 M Tris, $\mathrm{HCl} \mathrm{pH} \mathrm{9.0,} \mathrm{0.1} \mathrm{EDTA,} \mathrm{5 \%}$ (w/v) sucrose, $0.34(\mathrm{v} / \mathrm{v})$ diethilpyrocarbonate], before incubation at $65^{\circ} \mathrm{C}$ for $45 \mathrm{~min}$ in order to lyse cells and denature proteins. After cooling the sample on ice, $30 \mu \mathrm{l}$ of $8 \mathrm{M}$ potassium acetate was mixed with the homogenate, which was incubated on ice for $45 \mathrm{~min}$ before pelleting the contaminating proteins for 2 min at $14 \mathrm{k} \mathrm{rpm}$ in a microcentrifuge. The nucleic acids in the supernatant were then ethanol precipitated and washed three times in $70 \%$ ethanol (spinning at $14 \mathrm{k} \mathrm{rpm}$ in a micro-centrifuge), before drying the final pellet under vacuum and dissolving it in $15 \mu \mathrm{l}$ of $1 \mathrm{x}$ TE. Extracts were stored at $4^{\circ} \mathrm{C}$.

For differently screening, the genomic library made with DNA extracted from Dom Elizeu population, the methods of Ready et al. (1991) were used.

Of six recombinant clones obtained, two were selected for large-scale amplification, and one (W1) was used for hybridization, using serial dilutions of dot-blotted genomic DNA.

This technique was performed manually by directly applying a series of $2 \mu \mathrm{l}$ volumes from a Gilson pipette to the dry membrane, each application being allowed to dry: this was followed by in situ alkali lysis and neutralization. Following transfer, the membranes were rinsed briefly in $2 \mathrm{x}$ SSC [0.3 M NaCl, 0.03 M Tri-Na citrate] and air dried ( Ready et al. 1988, Sambrook et al. 1989, Smith et al. 1989).

Phylogenetic analysis - Phylogenetic analysis is considered as a traditional method in the study of biological systematics and is related to the relationship between species (Hennig 1966). Such an analysis indicates the apomorphic characters which are found in the members of a given group of organisms and which determine their evolutionary lines. Hennig (1966) and Abe and Papavero (1992) suggest the use of any character, including morphology, molecular biology, biology, ecology and others, in the comparative studies of different populations of the same species or of different species.

The following visible characters which are considered useful in separating sand flies species and which could be analyzed in all the examined material, were used for comparing populations of Lu. whitmani s.l. (in-group) and Lu. flaviscutellata and $\mathrm{Lu}$. ubiquitalis (out-groups):

Morphological characters included aspects of antennal ascoids, 5th palpal segment, teeth of maxilla, colour of scutelum, appearance of the body and common duct of the spermathecae, dermal papillae of tergites, head of spermathecae, male and female terminalia, internal spine of style, setae tuft of coxite.

Morphometrical characters of the females flies used were measurements of the labrum, the vein $\alpha$ of the wing, tibia and femur. Of the males the, tibia genital filaments and the genital filaments/ genital pump ratio.

Biochemical characters used were restricted to the results of the hybridization attempts using the DNA probe $\mathrm{W} 1$.

Biological characters included the degree of anthropophily, feeding habits, habitat and stratification.

After noting the different character states in the in-group, two matrixes were formulated: the first comparing the characters between the ingroup and the out-groups, and the second comparing the populations of the in-group only. Finally, a cladogram was prepared.

Throughout this paper Leishmania is abbreviated to Le. and Lutzomyia to $L u$. We follow the classification of Leishmania suggested by Lainson and Shaw (1987).

\section{RESULTS}

Morphology - Using 32 structural characters of the head, thorax and abdomen of both sexes of the sand flies, as recomended by CIPA Group (Bermudes et al. 1991), we could detect no significant morphological differences between the type material (paratype and holotype) of Lu.whitmani from Ilhéus and specimens of $L u$. whitmani s.l. from other parts of Bahia, Ceará and Pará.

Morphometry - In a consideration of 30 morphometric characters, statistical analysis could detect some significant differences between the northeastern flies and those from the differents areas of Pará, involving the following structures of the head, thorax and abdomen: in the females differences in the length of the labrum, tibia and femur; in the males - differences in the length of 
the 2nd and 3rd palpal segments, the maximum width of the wings and the length of vein R5, length of the tibia, femur, genital filaments and the genital filaments/genital pump ratio.

Biochemical studies (DNA probe and hybridization experiments) - Genomic DNA fragments of Lu. whitmani, using Amazonian material, were applied as diagnostic probes. Of six recombinants clones screened with total genomic DNA, two gave strong or moderate signals after high stringency washes and overnight autoradiography and, therefore, were assessed as containing sequences that are highly or moderately repeated in the genoma of this sand fly population. These two recombinant clones were selected for hybridizations. When the probe $\mathrm{W} 1$ was used, strong hybridizations signals were obtained only with the populations from Jari and Dom Elizeu (State of Pará, north and south of the Amazon river, respectively) and slightly or with none of the peridomestic $L u$. whitmani tested from Baturité and Ilhéus (Fig. 2).

Phylogenetic analysis - The main object of this study was to test the hypothesis that the northern and northeastern populations of $\mathrm{Lu}$. whitmani are not identical.
Firstly, each of 25 characters was defined (present $=+$ and absent $=-$ or, according to the intuitive Theory of Sets (Abe \& Papavero 1992) $+=$ to belong, and $-=$ not to belong) in the ingroup (i.e. populations of Lu. whitmani s.l.). After comparing the characters of the in-group and the out-groups (i.e. Lu. flaviscutellata and the Lu. ubiquitalis, s.l. populations) (Table I), a matrix was constructed showing the apomorphic characters $(=1)$, which appeared, in such an evolutionary line, posteriorly to the plesiomorphic characters $(=0)$ (Table II).

Using according to the Intuitive Theory of Sets, the following were determined:

a) The collections of apomorphies in each population:

Pará $(\mathrm{PA})=\{14,15,16,17,19,23,24,25\}$

Ceará $(\mathrm{CE})=\{12,18,20,21,22,24,25\}$

Bahia $(\mathrm{BA})=\{12,13,18,20,21,22,24,25\}$

b) The autapomorphies of the hypothetical ancestral form showing that the taxa are monophyletic groups:

(1) $\mathrm{PA} \cap \mathrm{CE} \cap \mathrm{BA}=\{24,25\}$

c) The autapomorphies for each population:

$\mathrm{PA}-(1)=\{14,15,16,17,19,23\}$

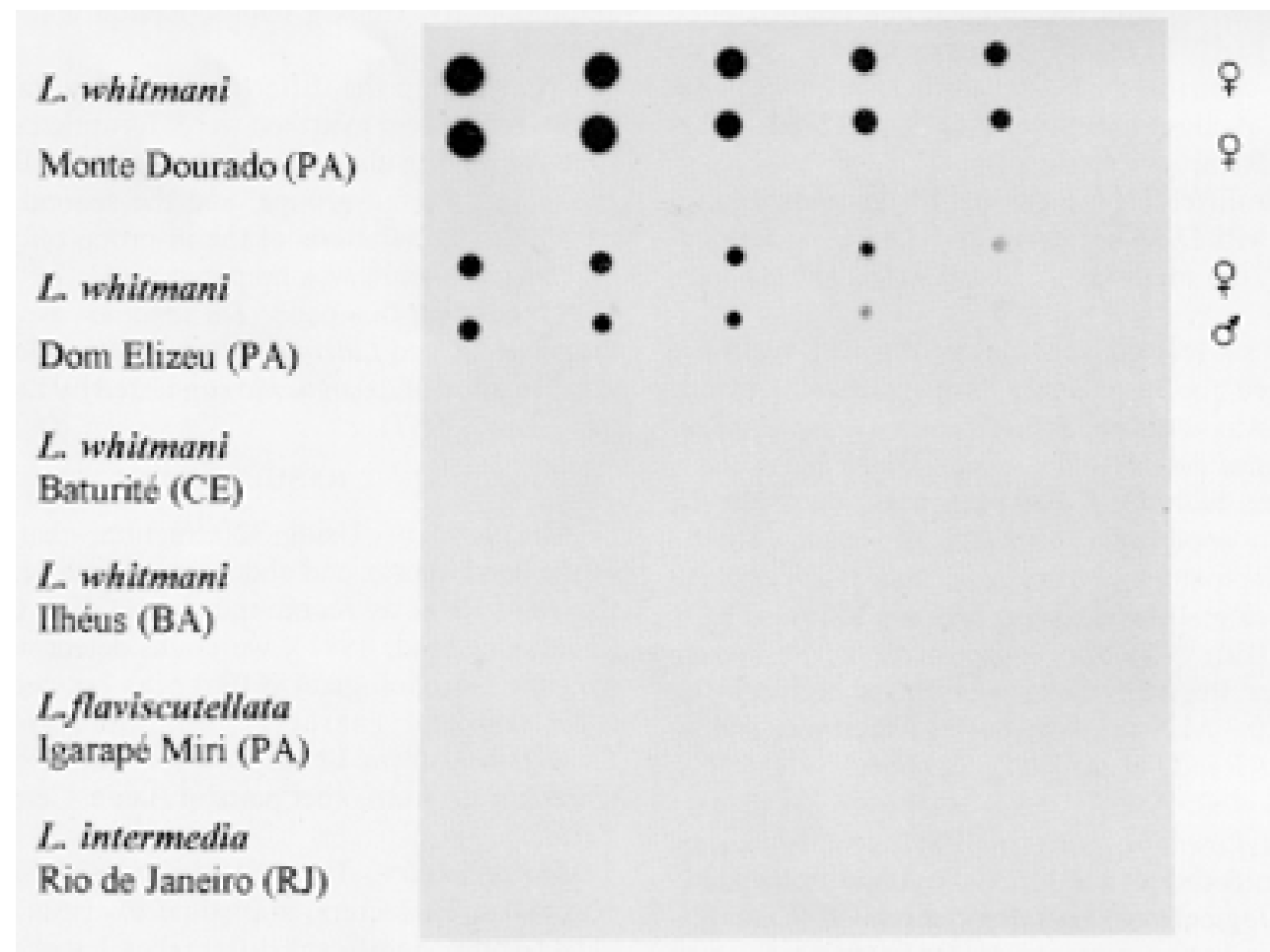

Fig. 2: Lutzomyia whitmani s.l. Hybridizations using the DNA probe W1, prepared from the sand flies from Dom Elizeu, State of Pará, react only with dot-blotted genomic DNA of sand flies from the same locality, and from Monte Dourado, another collection site in Pará. 
TABLE I

Lutzomyia whitmani s.l. Morphological, morphometrical, biological and biochemical characters state in populations from States of Bahia (type locality, BA), Ceará (CE) and Pará (PA), compared with the out-groups, Lu. flaviscutellata and Lu. ubiquitalis

\begin{tabular}{lcccccc}
\hline & \multicolumn{3}{c}{$\begin{array}{c}\text { In-Group } \\
\text { Lu.whitmani }\end{array}$} & & & Out-Group \\
& PA & CE & BA & Lu. flaviscutellata & Lu. ubiquittalis \\
\hline 1. antennal ascoids & + & + & + & + & + \\
2. 5th papal segment & + & + & + & + & + \\
3. spermathecae bodies & + & + & + & + & + \\
4. common duct & + & + & + & - & - \\
5. teeth of maxilla & + & + & + & + & - \\
6. dermal papilla on tergite & - & - & - & + & - \\
7. spermathecae head & - & - & - & + & + \\
8. permathecae common duct & - & - & - & + & \\
9. internal spine in style & - & - & - & - & \\
10. color of scutellum & - & - & - & - & \\
11. setae tuft on coxite & - & - & - & - & \\
12. labrum of female & - & + & + & - & \\
13. vein $\alpha$ of wing of female & - & - & + & - & \\
14. femur of female & + & - & - & - & \\
15. tibia of female & + & - & - & - & \\
16. tibia of male & + & - & - & - & \\
17. genital filaments & + & - & - & - & \\
18. relationship genital & - & + & + & - & \\
filaments/genital pump & & & & - & \\
19. DNA probe Wl & + & - & - & - & \\
20. anthropophily & - & + & + & - & \\
21. domestic habitat & - & + & + & - & \\
22. feeding habitats & - & + & + & - & \\
23. stratification & + & - & - & - & \\
24. female terminalia & + & + & + & - & \\
25. male terminalia & + & + & + & - & \\
\hline & & & & - & \\
\end{tabular}

$$
\mathrm{CE}-(1)=\{12,18,20,21,22\}
$$$$
\mathrm{BA}-(1)=\{12,13,18,20,21,22\}
$$

A cladogram showing that Lu. whitmani s.l. from Pará is different from $L u$. whitmani sensu stricto from the northeast of Brazil is given in Fig. 3, using the following characters: length of the femur and tibia of the female, tibia of the male and genital filaments; stratification, and hybridization with DNA probe $\mathrm{W} 1$. The monophily in the populations from the northeast is confirmed by anthropophily, domestic habitat, feeding habits and the length of the labrum of the female and the genital filaments/genital pump ratio in the males.

The results confirm the hypothesis that the populations of $\mathrm{Lu}$. whitmani studied are different and, indicate that the populations from north and northeastern Brazil can be considered as morphospecies, in accordance with Hennig (1966).

\section{DISCUSSION}

These studies leave little doubt in our minds that the sand fly for so long referred to as " $L u$. whitmani" in Amazonian Brazil is not the same as the true $L u$. whitmani (Antunes \& Coutinho 1939), from the type locality of Ilhéus, Bahia, or from Baturité, Ceará, and that we are probably dealing with two different, cryptic species.

The one, in Amazônia, is esentially silvatic, poorly anthropophilic, with no tendency to invade human dwelling-places, and concerned in the transmission of zoonotic cutaneous leishmaniasis of man due to Le. (V.) shawi. The other, Lu. whitmani sensu stricto, of southern and northeastern Brazil, was probably silvatic originally, but readily adapts to new ecological situations created by man's destruction of the native forest, and is now firmly established in the domiciliary and peridomestic habitats. This fly is highly anthropophilic, and one of the vectors of $\mathrm{Le}$. (V.) braziliensis s.l.

The results of our studies provide good evidence that these populations from northern and northeastern Brazil are not identical. The genital filaments/genital pump ratio was significantly smaller in sand flies collected in forest sites from 


\section{TABLE II}

Lutzomyia whitmani s.l. Matrix with characters polarity $(0=$ plesiomorphic state; $1=$ apomorphic state $)$, comparing specimens from Bahia, BA (type locality) and populations from northeastern Brazil (Ceará, CE, and Pará, PA).

\begin{tabular}{lccc}
\hline & \multicolumn{3}{c}{$\begin{array}{c}\text { In-Group } \\
\text { Lu. whitmani }\end{array}$} \\
\hline 5. teeth of maxilla & PA & CE & BA \\
6. dermal papilla on tergite & 0 & 0 & 0 \\
7. spermathecae head & 0 & 0 & 0 \\
8. permathecae common duct & 0 & 0 & 0 \\
9. internal spine in style & 0 & 0 & 0 \\
10. color of scutellum & 0 & 0 & 0 \\
11. setae tuft on coxite & 0 & 0 & 0 \\
12. labrum of female & 0 & 0 & 0 \\
13. vein $\alpha$ of wing of female & 0 & 0 & 1 \\
14. femur of female & 1 & 0 & 0 \\
15. tibia of female & 1 & 0 & 0 \\
16. tibia of male & 1 & 0 & 0 \\
17. genital filaments & 1 & 1 & 0 \\
18. relationship genital filaments/genital pump & 0 & 0 & 0 \\
19. DNA probe Wl & 1 & 1 & 1 \\
20. anthropophily & 0 & 1 & 1 \\
21. domestic habitat & 0 & 1 & 0 \\
22. feeding habitats & 0 & 0 & 1 \\
23. stratification & 1 & 1 & 1 \\
24. female terminalia & 1 & 1 & \\
25. male terminalia & 1 & 0 & \\
\hline
\end{tabular}

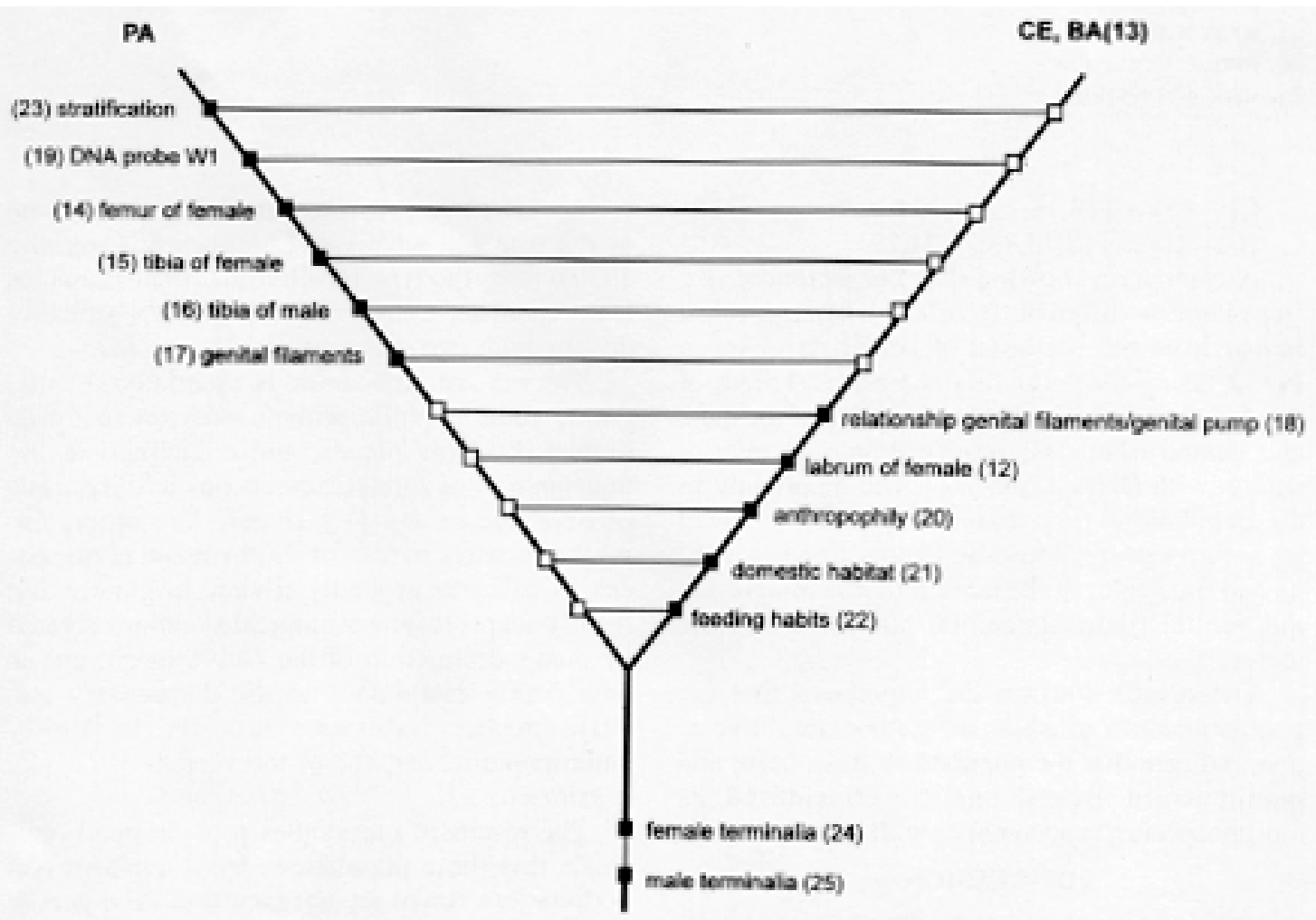

Fig. 3: Lutzomyia whitmani s.l. A cladogram showing that the populations from State of Pará are different from those in northeastern, Brazil. 
Pará than it was in sand flies collected from Baturité (CE) and Ilhéus (BA) in peridomestic sites, and both the tibia and femur were significantly shorter in Amazonian sand flies. Molecular evidence is provide by the probe $\mathrm{W} 1$, which is diagnostic for $L u$. whitmani from Pará and could not recognize specimens from States of Ceará and Bahia.

Our findings fit better, with the concept of a considerable sand fly/Leishmania specificity in nature (Lainson 1988), than with the alternative suggestion that Lu. whitmani is a highly adaptable sand fly, the habits of which are related to variable changes in the environment caused by man (Lainson 1983, Walsh et al. 1993).

It must be admitted that, even with the presented evidence, the Amazonian Lu. whitmani s.l. and $L u$. whitmani s.s. of northeast and southeast Brazil might be considered by some to be the two ends of a cline. Only further studies in other parts of the country, and (most important) cross-fertilization experiments will finally settle this question.

\section{ACKNOWLEDGEMENTS}

To Drs Nelson Papavero, for suggestions and critical revision, to Eunice $\mathrm{AB}$ Galati, for suggestions and Jair LF Santos, for the use of his computer program for means and standard deviations, all from São Paulo University; to technicians of the Section of Entomology, Evandro Chagas Institute, Belém (PA), for breeding sand flies.

\section{REFERENCES}

Abe JM, Papavero N 1992. Teoria Intuitiva dos Conjuntos. Makron Books Ed., São Paulo, XV + 266pp.

Antunes PCA, Coutinho JO 1939. Notas sobre flebótomos sul-americanos. II. Descrição de Flebotomus whitmani n. sp. e da armadura bucal de algumas espécies. Bol Biológico IV: 448-451.

Armitage P 1971. Statistical Methods in Medical Research. Blackwell Scientific Publication, London, $504 \mathrm{pp}$.

Azevedo ACR, Rangel EF, Costa ME, David J, Vasconcelos AW, Lopes UG 1990. Natural infection of Lutzomyia (Nyssomyia) whitmani (Antunes \& Coutinho 1939) by Leishmania of the braziliensis complex in Baturité, Ceará State, Northeast Brazil. Mem Inst Oswaldo Cruz 85: 251.

Barretto MP 1943. Observações sobre a biologia em condições naturais dos flebótomos do Estado de São Paulo (Diptera:Psychodidae).Thesis, Universidade de São Paulo, 162pp.

Cipa Group. Bermudes H, Dedet JP, Falcão AL, Feliciangeli D, Ferro C, Galati EAB, Gomes EL, Herrero MV, Hervas D, Lebbe J, Morales A, Oguzuku E, Perez E, Rangel EF, Sherlock IA, Torrez M, Vignes R, Wolff M 1991. Proposition of a standard description for Phlebotomine sand flies. Parasitologia 33(Suppl.): 127-135.
Forattini OP 1960. Novas observações sobre a biologia de flebótomos em condições naturais (Diptera: Psychodidae). Arch Hyg Saúde Publ 25: 209-215.

Gomes AC, Rabello EX, Natal D 1985. Uma nova câmara coletora para armadilha CDC miniatura. Rev Saúde Públ, São Paulo 19: 190-191.

Hennig W 1966. Phylogenetic Systematic. University of Illinois Press, Urbana, 263pp.

Hock A, Ryan L, Vexenat JA, Rosa AC, Barreto AC 1986. Isolation of Leishmania braziliensis braziliensis and other trypanosomatids from Phlebotomine in a mucocutaneous leishmaniasis endemic area, Bahia, Brazil. Mem Inst Oswaldo Cruz 81: 63.

Ish-Horowicz D 1982. Rate of turnover of structural variants in the rDNA gene family of Drosophila melanogaster. Nature 295: 564-568.

Lainson R 1983. The American leishmaniases: some observations on their ecology and epidemiology. Trans $R$ Soc Trop Med Hyg 77: 569-596.

Lainson R 1988. Ecological interactions in the transmission of the leishmaniases. Phil Trans R Soc Lond B 321: 389-404.

Lainson R, Braga RR, Povoa M, Ishikawa Eay, Silveira FT 1989. Leishmania (Viannia) shawi sp.n., a new parasite of monkeys, slothsand procyonids in Amazonian Brazil. Ann Parasitol Hum Comp 64: 200207.

Lainson R, Shaw JJ 1987. Evolution, classification and geographical distribution. p.1-20. In W Peters, R Killick-Kendrick (eds), The Leishmaniases in Biology and Medicine, Academic Press, London.

Lainson R, Shaw JJ, Ward RD, Ready PD, Naiff RD 1979. Leishmaniasis in Brazil: XIII. Isolation of Leishmania from armadillos (Dasypus novemcinctus) and observations on the epidemiology of cutaneous leishmaniasis in North Pará State. Trans $R$ Soc Trop Med Hyg 73: 239-241.

Mayrink W, Williams P, Coelho MV, Dias M, VianaMartins A, Magalhães PA, Costa CA, Falcão AR, Melo MN, Falcão AL 1979. Epidemiology of dermal leishmaniasis in the Rio Doce Valley, State of Minas Gerais, Brazil. Ann Trop Med Parasitol 73: 123-137.

Queiroz RG, Vasconcelos IA, Vasconcelos AW, Souza RN, David J 1991. New World phlebotomine sandflies as hosts of Leishmania (V.) braziliensis in an endemic area for cutaneous leishmaniasis in Ceará State, Northeast Brazil. First International Symposium on Phlebotomine Sandflies, Rome, $87 \mathrm{pp}$.

Ready PD, Lainson R, Shaw JJ, Souza AA 1991. DNA probes for distinguishing Psychodopygus wellcomei from Psychodopygus complexus (Diptera: Psychodidae). Mem Inst Oswaldo Cruz 86: 41-49.

Ready PD, Lainson R, Shaw JJ, Ward RD 1986. The ecology of Lutzomyia umbratilis Ward \& Fraiha (Diptera:Psychodidae), the major vector to man of Leishmania braziliensis guyanensis in north-eastern Amazonian Brazil. Bull ent Res 76: 21-40.

Ready PD, Smith DF, Killick-Kendrick R 1988. DNA hybridization on squash-blotted sand flies to identify both Phlebotomus papatasi and infecting Leish- 
mania major. Med Vet Entomol 2: 109-116.

Ryan L, Vexenat JA, Marsden PD, Lainson R, Shaw JJ 1990. The importance of rapid diagnosis of new cases of cutaneous leishmaniasis in pin-pointing the sandfly vector. Trans R Soc Trop Med Hyg 84: 786.

Sambrook J, Fritsh EF, Maniatist T 1989. Molecular cloning, p. 10.2-10.7. In A Laboratory Manual, Cold Spring Harbor Press, New York.

Shaw JJ, Ishikawa EAY, Lainson R, Braga RR, Silveira FT 1991. Cutaneous leishmaniasis of man due to Leishmania(Viannia) shawi Lainson, De Souza, Póvoa, Ishikawa \& Silveira in Pará State, Brazil. Ann Parasitol Hum Comp 66: 243-246.

Sherlock IA, Pessoa SB 1964. Métodos práticos para a captura de flebótomos. Rev Brasil Biol 24: 331-340.

Smith DF, Searle S, Ready PD, Gramiccia M, BenIsmail R 1989. Akinetoplast DNA probe diagnostic for Leishmania major: sequence homologies between regions of Leishmania minicircles. Mol Biochem Parasitol 37: 213-224.

Sudia WD, Chamberlaim RW 1962. Battery-operated light trap, an improved model. Mosquito News 22: 126-129.

Taniguchi HH, Tolezano JE, Correa FMA, Moraes RHP, Veiga RM, Marassa AM 1991. Epidemiologia da leishmaniose americana no Estado de São Paulo,
Brasil. 1. Composição da fauna flebotomínica no Município de São Roque, Região de Sorocaba. Rev Inst Adolfo Lutz 51: 23-30.

Teodoro U, La Salvia $F^{o}$ V, De Lima EM, Misuta NM, Verginase TG, Ferreira ME 1991. American cutaneous leishmaniasis: phlebotomine of the area of transmission in the north of Paraná, Brazil. Rev Saúde Públ25: 129-133.

Tolezano JE, Novelli MA, Taniguchi HH 1992. Leishmaniose tegumentar no Estado de São Paulo. VI. Avaliação do comportamento antropofílico de flebotomíneos em áreas endêmicas. Mem Inst Oswaldo Cruz 87 (Suppl.): 219.

Walsh JF, Molyneux DH, Birley MH 1993. Deforestation: effects on vector-borne disease. Parasitology 106: 55-75.

Ward RD, Shaw JJ, Lainson R, Frhaia H 1973. Leishmaniasis in Brazil: VIII. Observations on the Phlebotomine fauna of an area highly endemic for cutaneous leishmaniasis in the Serra dos Carajás, Pará State.Trans R Soc Trop Med Hyg 67: 174-183.

Young DG, Duncan MA 1994. Guide to the identification and geographic distribution of Lutzomyia sandflies in Mexico, the West Indies, Central and South America (Diptera:Psychodidae). Mem Amer Ent Inst 54: 1-881. 